\title{
A REVIEW ON STUDY OF COMPOSITE MATERIALS IN PRESENCE OF CRACKS
}

\author{
Danai Abhijeet $\mathbf{R}^{\mathbf{1}}$, M.C.Swami ${ }^{2}$, Parmeshwar Patil ${ }^{\mathbf{3}}$ \\ ${ }^{1}$ M.E. Machine Design Student, Mechanical Department, M. S. Bidve Engineering College,Latur,Maharashtra,India \\ ${ }^{2}$ Assistant professor, Mechanical Department, M. S. Bidve Engineering College, Latur, Maharashtra, India \\ ${ }^{3}$ Assistant professor, Mechanical Department, G. N. D. Engineering College, Bidar, Karnataka, India.
}

\begin{abstract}
Composites materials are commonly used in automobiles, aircraft structures etc. due to their high specific strength and stiffness. Composites ability to retain functionality in the presence of damage is a crucial, safety and economic issue. The fatigue failure mechanisms have been widely studied. Matrix cracks, fiber break, dis-bonding and de-laminations are the main causes for progressive failure of composites under fatigue loads. In this paper, detailed review on composite in presence of cracks under different types of failure mechanisms etc have been discussed.
\end{abstract}

Keywords: Fatigue Failure Mechanisms, cracks in composite

\section{INTRODUCTION}

Composites are widely used in aircraft structures due to their high specific strength and stiffness. Composite structures for mechanical and aerospace applications are designed to retain structural integrity and remain durable for the intended service life. When the fiber reinforced composite laminates loaded mechanically or thermally, cracks are developed in the plies. These cracks are lies along the fibers in the plies and are known as ply cracks, matrix cracks, or transverse cracks. In presence of these cracks, laminates responds differently than in its original state and also failure is caused because of these cracks directly, they can lead to delamination and laminate failure. For structural integrity it is necessary to perform deformational and failure analysis of laminates with ply cracks [9].

\subsection{Fatigue Failure Mechanisms}

There are four types of failure mechanisms as follows

\subsubsection{De-Bonding}

The performance of a fiber reinforced composite is affected because of interface between the fiber and matrix resin. The interfacial de-bond plays very major role in stress transfer between fiber and matrix, adhesion bond at the interface, which affects the macroscopic properties of the composite Suppose, if the fiber and matrix are weakly held, then the composite starts to form a matrix cracks, also if fibers are strongly bonded to matrix, matrix cracking is delayed and composite fails catastrophically. Interfacial properties can control the performance of composite structure

\subsubsection{Matrix Cracks}

Matrix cracks are the first form of damage observed in fiberreinforced composites. Also these are not final form of failures, but small cracks come closer and forms bigger cracks. These cracks are then all along fiber and matrix. In given laminates these cracks can form in a given ply and grow along the thickness of ply and running parallel small to the fibers in that ply. Such cracks are found because of tensile loading, fatigue loading, as well as by changing in temperature or by thermal cycling. They can generated from fiber-matrix de-bonds or because of manufacturing defects like voids and inclusions. Matrix cracking does not cause structural failure by itself, but it results in significant degradation in material stiffness and can also develop more severe forms of damage such as de-lamination, and fiber breakage.

\subsubsection{De-Lamination}

It is defined as cracking in the interfacial plane between two adjoining plies in a laminate cause's separation of laminae is called as de-lamination. In composite, de-lamination can occur at cut or free edges, like at holes, or at an exposed surface through the thickness. De-lamination can also form because of low viscosity impact. As compared to metals, in polymer composite laminates de-lamination can occur below the surface of a structure, but while visual inspection surface appears unchanged. The growth of the de-lamination crack under the external loads leads to a rapid reduction of the mechanical properties and may cause catastrophic failure of the composite structure. The de-lamination can grow and separate the region.

\subsubsection{Fiber Breakages}

Many times failure of fiber reinforced composite is takes place because of breakage of fibers. When a unidirectional composite loaded in tension along fibers, the individual fiber fails at their weak points and stress redistribution between fibers and matrix occurs. This affects the other fibers and possibly breaking some other fibers. At the interface between fiber-matrix stress transfer takes place from broken fiber to the other fiber at a certain distance which makes another fiber break 


\subsubsection{Literature Review}

S.Li, C.V. Singh studied about Representative Volume element for the analysis of laminated composites which contains two arrays of ply cracks running in different directions. Finite element stress analysis is performed for few cases to illustrate the results like crack surface displacements, local stress and RVE average elastic properties. For one case the average properties are compared with experimental results. For finite element analysis Abaqus software is used [1]. Chandra veer singh, studied about the analysis of multiple off axis ply cracks in composite laminates, for this analysis synergistic methodology is used to analyze damage behavior in composite. The micromechanics are performed on a representative unit cell using three dimensional finite analyses to calculate crack opening displacement. The crack opening displacement and stiffness degradation predictions are compared with published experimental data [2]. Chandra veer singh treats a evolution of ply cracks in multidirectional composite laminates subjected to a quasi static tensile load in the longitudinal direction. It starts with pre-existing ply cracks in off axis plies; the formation of additional cracks is analyzed by an energy based approach. A critical laminate energy is defined and is evaluated using experimental data. The modeling approach is calculated by a three dimensional finite element analysis and is performed on representative volume element of a given cracked laminates. Analytical and experimental data were compared [3]. J. N. Nairn studied about the initiation and growth of the de-laminations in composite laminates. Two dimensional stress analyses are performed to calculate total strain energy, effective modulus and longitudinal thermal expansion for a laminate having microcracks and de-laminations. These results were used to calculate energy release rate for initiation and growth of the de-lamination also a three dimensional model was used to predict the propagation of de-lamination all analytical and experimental data were compared [4]. Ramesh Talreja discuses about the damage mechanics, specific topics which are highlighted here are fatigue damage mechanisms, characterization of damage and its evolution, criticality of damage and fatigue life prediction. Available data and analysis results were compared and discussed [5]. Janis Varna studied about the crack opening displacement and associated response of laminates. Researcher reports an experimental study of crack opening displacement behavior of $90^{\circ}$ ply cracks in composite laminates with varied constraint effect [6]. J. Qu, K. Hoiseth studied about the transverse matrix cracking in cross ply laminates. Micromechanics model is develop to study the transverse matrix cracking by a combination of finite element and analytical analysis. The predicted data and experimental data were compared. Stress-strain curves are also obtained for material systems. The analytical results were compared with finite element calculations [7]. Jae Noh and John Whitcomb discusses about the de-lamination, damage growth and opening near intersection of transverse matrix cracks. Three dimensional finite element analyses were used to analyze the laminates. Material used here for analysis is graphite epoxy. The strain energy release rates were calculated for de-lamination based on crack closure technique, de-lamination shape and size for cross and angle ply laminates were determined [8].

\section{CONCLUSION}

Analysis of composite in presence of cracks and fatigue life prediction under variable amplitude loads has been attempted by various investigators in the past. Different types of analytical models have been employed by the several authors to predict fatigue life. However, accuracy of predictions has been observed to vary significantly. Although micro-mechanics based models have yielded good results. The fatigue failure mechanisms matrix cracks, disbonding, de-laminations and fiber break, are the main causes for progressive failure of composites under fatigue loads. We need proposed to systematically model and analyze the defects to estimate the stiffness degradation of composites by considering failure mechanisms.

\section{ACKNOWLEDGEMENTS}

I would like to thank Prof.M.C.Swami for motivating me to undertake the project in comparative study of leaf springs. I would also like to thank, Prof.S.G.Mantri, Prof.K.S.Upase, Londhe A.B providing me the Technical Knowledge.

\section{REFERENCES}

[1]. Chandra veer singh,Ramesh Talreja "Analysis of multiple off-axis ply cracks in composite laminates", International Journal of Solids and Structures 45 (2008) 4574-4589@ 2008 Elsevier Ltd.

[2]. S. Li 1, C.V. Singh, R. Talreja," A representative volume element based on translational symmetries for FE analysis of cracked laminates with two arrays of cracks" S. Li et al. / International Journal of Solids and Structures 46 (2009) 1793-1804. @ 2009 Elsevier Ltd.

[3]. Chandra Veer Singh, Ramesh Talreja," Evolution of ply cracks in multidirectional composite laminates", C.V. Singh, R. Talreja / International Journal of Solids and Structures 47 (2010) 1338-1349. . @ 2010 Elsevier Ltd.

[4]. J. A. NAIRN and S. Hu," The initiation and growth of de-laminations induced by matrix microcracks, in laminated composites", international Journal of fracture 57:1-24,1992.

[5]. Ramesh Talreja, "Damage Mechanics and Fatigue Life Assessment of Composite Materials" International Journal of Damage Mechanics 1999 8: 339,@ SAGE

[6]. Janis Varna, Nagendra V. Akshantala and Ramesh Talreja," Crack Opening Displacement and the Associated Response of Laminates with Varying Constraints", International Journal of Damage Mechanics 1999 8: 174 $@$ SAGE

[7]. J. QU and D K. HOISETH," evolution of transverse matrix cracking in cross-ply laminates", fatigue \& fracture of engineering materials \& structures 1998; 21: 451-464 [8]. JAE NOH AND JOHN WHITCOMB," Prediction of De-lamination Growth and Opening near Intersection of Transverse Matrix Cracks and De-lamination", Journal of COMPOSITE MATERIALS, Vol. 39, No. 15/2005, @ 2005 Sage Publications.

[9]. Ramesh Talreja and Chandra veer Singh"Damage and Failure of composite materials" 


\section{BIOGRAPHIES}

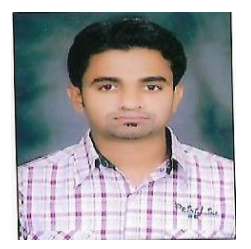

Danai Abhijeet R., (Student of M.E.

Machine Design)

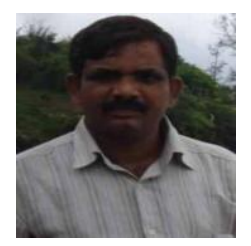

Prof. M. C. Swami, Assistant Professor



Prof. P. S. Patil, Assistant Professor 